\title{
Comparative Evaluation of Zea mays (L.) and Ipomoea batatas (L.) as a Pharmaceutical Excipient
}

\author{
Md. Mahadi Hasan ${ }^{1}$, Sanchita Sharmin Chowdhury ${ }^{2}$, Shah Marzia Mahjabin \\ Lina $^{3}$, Nikhil Chandra Bhoumik ${ }^{4}$ and Imran Ashab ${ }^{5}$ \\ ${ }^{1,2}$ Department of Pharmacy, Jahangirnagar University, Savar, Dhaka-1342, Bangladesh \\ ${ }^{3}$ Department of Pharmacy, Stamford University, Dhaka-1217, Bangladesh \\ ${ }^{4}$ Wazed Miah Science Research Centre, Jahangirnagar University, Savar, Dhaka-1342, Bangladesh \\ ${ }^{5}$ Department of Pharmacy, Daffodil International University, Dhaka-1207, Bangladesh
}

\begin{abstract}
This investigation aims at comparing starches from two grains: Maize (Zea mays) and Sweet potato (Ipomoea batatas) grains. These grains are used mainly as foods and they contain high amount of carbohydrate. The presence of starch in these grains varies and thus their use as pharmaceutical excipients will vary to the degree of their starch functionality. The powders obtained were characterized for their particle size, particle size distribution. The organoleptic and physicochemical characterization such as viscosity, hydration capacity, swelling capacity, moisture sorption capacity, $p H$, flow rate and porosity, Carr's index and Hausner's ratio were evaluated. Maize starch showed the least Carr's index, Hausner ratio, porosity, moisture sorption capacity and the greatest flow rate. Sweet potato starch showed the highest hydration capacity and swelling capacity. The results obtained showed that between the two starches in relation to their flowability, maize starch possesses the best flow property. Compatibility of Etoricoxib with maize and sweet potato starch was evaluated by IR spectra and found that both Etoricoxib is compatible along with maize and sweet potato starch. This knowledge of starch properties will help to explain the behavior of these starches when used as tablet excipients.
\end{abstract}

Key words: Starch, Carbohydrate, Flow ability, Etoricoxib.

\section{Introduction}

The characterization of pharmaceutical excipients using a material science approach has helped to design drug formulations to obtain a desired set of performance properties. For tablets, a better understanding of the compression properties of the material alone and in combination with other potential components helps in developing desirable formulations as well as acceptable products (1). When formulating tablets, the choice of excipients is extremely critical. It must fulfill certain requirements such as compressibility, good binding functionality, powder crystallinity, flowability and acceptable moisture content. Moreover, it is essential to have a well designed particle size distribution for favorable mixing conditions with drugs $(2,3)$.

Starch is widely used as thickening, stabilizing, gelling and/or filling agent in many food applications and it considered as the most used excipients in pharmaceutical formulations. It has many pharmaceutical applications and it is used mainly in tablets as filler, binder or disintegrant (4). Starch is the major carbohydrate reserve in plant tubers and seed endosperm where it is found as granules. It contains mainly two types of polymer molecules; several million of highly branched amylopectin molecules (normally 70-80\%) accompanied by a higher number of largely linear amylase molecules (normally 20-30\%) (5). Starches obtained from different botanical sources may not have identical properties with respect to their use for specific pharmaceutical purposes. Examples of starch sources are maize, rice, potato and wheat (6). Currently, only few materials meet the criteria to allow starch classification as tablet excipient and to study the relation between their pharmaceutical properties and their source, cultivation and production $(7,8)$. An understanding of the physicochemical properties of starch is critical for its proper use.

The aim of this study is to investigate the properties of starches and also study their advantages and disadvantages relative to each other. The objectives therefore are, to extract maize and sweet potato starches from their natural plant sources and process them to pharmaceutical grade starch and to compare the physical properties of these starches in the powdered state relative to each other.

\section{Materials and Methods}

Collection and Identification of Starches

Maize (Zea mays) and Sweet potato (Ipomoea batatas) were purchased from BADC market at Mohahammadpur in Dhaka and were identified by Department of Botany, Faculty of Biological Sciences in Jahangirnagar University, Bangladesh. 


\section{Extraction of Maize and Sweet potato starches}

The outer layer of sweet potato was peeled off and the white part was washed and cut into the pieces. Then it was powdered in a blender (Philips HR2001, China). Then it was washed with enough quantity of distilled water. The washing steps were repeated until the supernatant was clear and the starch was free of color. The starch was then dried in an air oven at $105^{\circ} \mathrm{C}$. The procedure was also same for the maize or corn flower powder. (9).

\section{Characterization of Starch Solubility test}

$1 \mathrm{~g}$ of each starches (Maize and Sweet Potato) were weighed and poured into a beaker containing $1 \mathrm{ml}$, $2 \mathrm{ml}, 10 \mathrm{ml}, 1 \mathrm{~L}$ and $10 \mathrm{~L}$ distilled water at $25^{\circ} \mathrm{C}$ and was stirred, and the solubility was observed. Same procedure was repeated using $65 \%$ alcohol as a solvent.

\section{Iodine test}

Using BP (2010) starch identification test, $1 \mathrm{~g}$ of each starches (Maize and Sweet Potato) were boiled with $15 \mathrm{ml}$ of water and allowed to cool. A few drops of $0.1 \mathrm{~N}$ Iodine solution were added to $1 \mathrm{ml}$ of the mucilage and the color changes recorded.

\section{Determination of $P^{H}$}

One gram (1g) of the individual starches was made into mucilage with $100 \mathrm{mls}$ of distilled water and the $\mathrm{pH}$ was determined in an electronic $\mathrm{P}^{\mathrm{H}}$ meter.

\section{Moisture Content Determination}

One gram $(1 \mathrm{~g})$ of the powder was weighed and then dried in an oven at $105^{\circ} \mathrm{C}$ for about 1 hour and then weighed again until constant weight was gotten and the percentage of loss on drying was calculated.

Moisture content $=\left(\mathrm{W}_{\mathrm{f}} / \mathrm{W}_{\mathrm{i}}\right) \times 100 \ldots \ldots-\ldots$

Where, $\mathrm{W}_{\mathrm{f}}$ is final weight of powder after drying and $\mathrm{W}_{\mathrm{i}}$ is initial weight of powder before drying.

\section{Microscopic Determination}

A small quantity of each starch was mounted in a drop of glycerol on a glass slide and covered with a slip. The size and shape of starch particles were determined with a microscope (Olympus, Germany) equipped with a micometer using $40 \times$ magnification.

\section{Determination of flow properties of starch}

Angle of repose

Angle of repose was measured for the starch batches before granulation, as to observe the flow properties of starch particles. The method employed a funnel secured with its tip at a given height $(h)$, above the graph paper placed on horizontal surface. Starch powders were poured through the funnel until the apex of the conical pile touches the tip of the funnel. The angle of repose was calculated using the following formula:

$$
\tan \varnothing=\mathrm{h} / r-\ldots \ldots
$$

Where, $\varnothing$ is the angle of repose and $r$ is the radius of conical pile.

The mean angle of repose was calculated from three determinations. This method is known as fixed height method.

\section{Determination of Starch density \\ Bulk and Tapped densities}

Bulk and Tapped densities were determined by using 50g ( $W p)$ of the starch powder. This was gently poured through a short stemmed glass funnel into a $100 \mathrm{ml}$ graduated cylinder. The volume occupied by the powder is taken as $V p$. The powders were tapped on a wooden surface at height of 7 inches until no further change in volume was observed. This volume $(V p T)$ was taken as the tapped volume.

$$
\begin{aligned}
& \mathrm{B}_{\mathrm{d}}=(\mathrm{Wp} / \mathrm{Vp})-\ldots-\ldots-\ldots-\ldots \text { (iii) }
\end{aligned}
$$

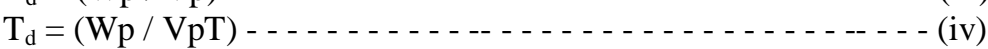

Carr's Index

The difference between the tapped and bulk density divided by the tapped density was calculated and ration expressed as a percentage.

\section{Hausner Ratio}

The ratio of tapped density to bulk density was calculated for all starches. 


\section{Determination of starch true density}

The specific gravity bottled method was adopted, and xylene was used as displacement fluid. The bottle was cleaned and filled with xylene, all spilled over liquid (xylene) was wiped off with an absorbent cloth. The weight of the bottle filled with xylene was noted as (a), the bottle was emptied and cleaned, $2 \mathrm{~g}$ of starch was weighed into the specific gravity bottle, the weight of the starch powder was noted as (w). The specific gravity bottle containing the starch was almost filled with xylene, stirred with glass rod and allowed to stand for 10 minutes for air bubbles to be released. The bottle was then carefully filled with xylene and the final weight of the bottle was noted as (b). Starch true density was calculated as:

$1=\mathrm{w} /[(\mathrm{a}+\mathrm{w})-\mathrm{b}] \mathrm{S}$

Where, 1 is the particle density of starch and the specific gravity of xylene, $S=0.86$

\section{Swelling capacity}

The swelling capacity of the starch powders were determined by the method of Iwuagwu and Okoli (10). The tapped volume occupied by $5 \mathrm{~g}$ of the powder $\mathrm{V}_{\mathrm{x}}$ was noted. The powder was then dispersed in $85 \mathrm{ml}$ of distilled water and the volume made up to $100 \mathrm{ml}$ with more water. After 24 hours of standing, the volume of the sediment, $\mathrm{V}_{\mathrm{v}}$ was estimated and the swelling capacity, $\mathrm{S}$, was computed as:

$\mathrm{S}=\left[\left(\mathrm{V}_{\mathrm{v}}-\mathrm{V}_{\mathrm{x}}\right) / \mathrm{V}_{\mathrm{x}}\right] \times 100 \ldots \ldots(\mathrm{ni})$

\section{Moisture sorption capacity}

Moisture sorption capacity of the starch was determined by modified method of Ohwoavworhua et al, (11). Two grams $(2 \mathrm{~g})$ of the individual starch powders $(\mathrm{W})$ were weighed and put into a tarred Petri dish. The samples were then placed in a desiccator containing distilled water at room temperature and the weight gained by the exposed samples at the end of a five-day period $\left(\mathrm{W}_{\mathrm{g}}\right)$ was recorded and the amount of water absorbed $\left(\mathrm{W}_{\mathrm{a}}\right)$ was calculated from the weight difference as:

$\mathrm{W}_{\mathrm{a}}=\mathrm{W}_{\mathrm{g}}-\mathrm{W} \ldots \ldots$. . . . (vii)

\section{Hydration capacity}

A $1 \mathrm{~g}$ weight of starch was in placed $15 \mathrm{ml}$ plastic centrifuge tube, $10 \mathrm{ml}$ distilled water was added and then closed. The contents were shaken for $2 \mathrm{~min}$ and then allowed to stand for $10 \mathrm{~min}$ and immediately centrifuged at $1000 \mathrm{rpm}$ for $10 \mathrm{~min}$ in a bench centrifuge. The supernatant water was decanted and the weight of the wet starch was recorded. The hydration capacity was determined using the equation below:

Hydration capacity $=\mathrm{W}_{\mathrm{S}} / \mathrm{W}_{\mathrm{D}}$

Where, $\mathrm{W}_{\mathrm{S}}$ and $\mathrm{W}_{\mathrm{D}}$ are the weights of the sediment formed and weight of the dry sample respectively.

\section{Porosity}

The powder porosity (E) was calculated by the method of Ohwoavworhua and Adelakun (12) as:

$$
\mathrm{E}=\left[1-\left(\mathrm{B}_{\mathrm{d}} / \mathrm{D}_{\mathrm{t}}\right)\right] \times 100 \ldots \text {. . . . . . . . . . . . . . . }
$$

Where, $B_{d}$ is bulk density, $D_{t}$ is true density of starch.

\section{Packing fraction}

The packing fraction $\left(\mathrm{P}_{\mathrm{f}}\right)$ was expressed as the ratio between the bulk density $\left(\mathrm{B}_{\mathrm{d}}\right)$ and the true density $\left(\mathrm{D}_{t}\right)$;

$$
\mathrm{P}_{\mathrm{f}}=\left(\mathrm{B}_{\mathrm{d}} / \mathrm{D}_{\mathrm{t}}\right) \ldots \ldots \ldots
$$

\section{FT-IR compatibility test}

Compatibility of Etoricoxib, a widely prescribed NSAIDs in Bangladesh with maize starch and sweet potato starch was studied by IR spectra (Shimadzu FT-IR 8400S, Japan).

\section{Result and Discussion}

The percentage yield obtained from extracting starch from Maize (Zea mays) and Sweet potato (Ipomoea batatas) was 48.8 and 40.8 respectively. The higher yield and low cost of these starches indicate that it can be potential source of pharmaceutical raw material.

The identification tests carried out showed that Maize and Sweet potato starches were insoluble in water and alcohol (95\%) at room temperature. The starches were all positive to mucilage and iodine tests. Sweet potato starch was more acidic than the maize starch as shown in table 1 . The nearness of the starches to $\mathrm{pH} 7$ could be an advantage because neutral $\mathrm{pH}$ might decrease tendency of interaction of excipients with active pharmaceutical ingredient. The $\mathrm{pH}$ was all within the acceptable limit of 4.5-8 [13]. The color, odor, taste, solubility test for this two starches were within the official recommendation (BP. 2010).There is no color and taste was found in both starches (Table 1). 
Table 1: Results of identification tests of Maize and Sweet Potato starch

\begin{tabular}{|c|c|c|}
\hline Parameter & Maize & Sweet Potato \\
\hline Color & White & Yellowish \\
\hline Odor & Odorless & Odorless \\
\hline Taste & Tasteless & Tasteless \\
\hline Test for mucilage & Positive & Positive \\
\hline Solubility test & Insoluble & Insoluble \\
\hline Iodine test & Positive & Positive \\
\hline $\mathrm{P}^{\mathrm{H}}$ & 5.96 & 6.22 \\
\hline
\end{tabular}

\section{Microscopy of starch}

Figure 1 - 2 shows the photomicrograph of the starches at X40 magnification. Maize starch particle were small angular polyhedral and round (Fig.1). The particle shapes of the sweet potatoes starch were mainly spherical and polyhedral. The large particle size is an advantage because large particle has smaller surface area and hence smaller surface activity. Larger particles flow better than smaller particles because particulate function is more of surface phenomenon by generation of resistance to flow. The smaller particles (large surface area) having more surface energy to attract with one another tends to adhere together have more resistance to flow [14]. It is however pertinent to note that not only particle size that is involved in the flow of powders, other characteristics of excipients such as densities and moisture content may also affect flow properties of powder.
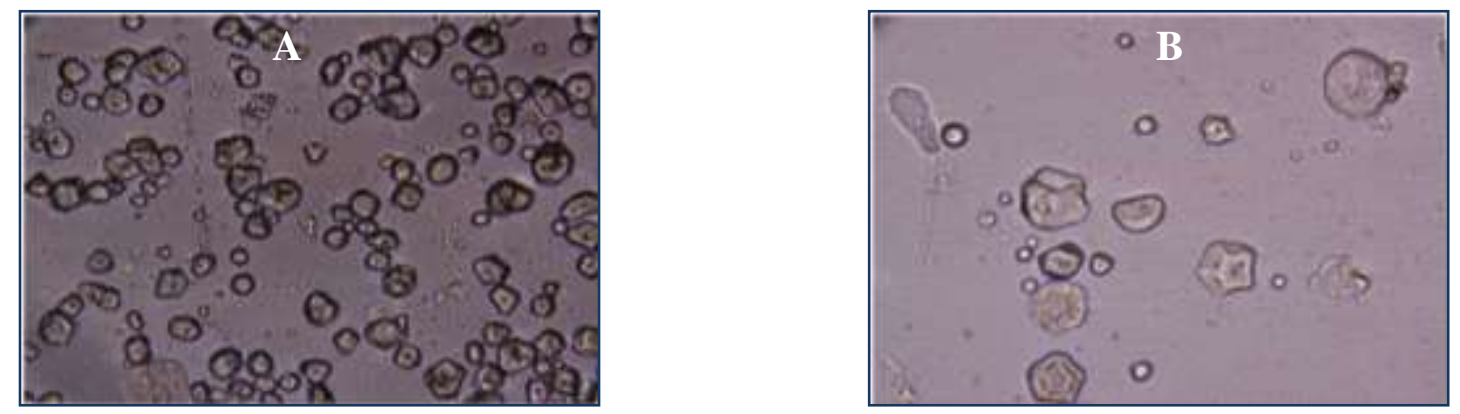

Figure 1: Photomicrograph of maize starch (A) and sweet potato starch (B) at X40 magnification.

\section{Physicochemical parameters of starch}

The physicochemical parameters of the starch were presented in table 2 the hydration capacity of starch sweet potato starch was higher than that of the maize starches. It is assumed that the hydration of starch represents the water absorbed by the particle or the particle surface (14). As observed earlier, the smaller the particle size, the larger the surface area for absorption of water. The sweet potato starch has higher moisture content than maize starch this might be as a result of larger particle size of the potato starch. Regulation of moisture in formulation is very important as high moisture content may interfere with active ingredient (15). The moisture sorption capacity is a measure of moisture sensitivity of a material and it reflects the relative physical stability of the tablets formulated with the material when stored under humid conditions (16). The results show that maize starch absorbed the least moisture followed by sweet potato starch. This could indicate that maize starch when used in tablet formulation would absorb the least moisture and thus eventually give tablets with better physical stability than sweet potato. The common feature of all theories of disintegration is that penetration of water (or liquid medium) must precede disintegration and this can be assessed by the determination of hydration capacity, swelling capacity and porosity (17). The hydration capacity of the starches indicates that both maize and sweet potato starch is capable of absorbing two times its own weight of water. The swelling capacity which reflects increase in volume of the starches showed sweet potato starch having the highest increase in volume followed by maize. This suggests that sweet potato starch may be a better disintegrant than the other starch and if incorporated in tablet formulation as a disintegrant, would probably produce tablet disintegration by two mechanisms: capillary or wicking and swelling.

Also from the results of bulk, tapped densities, porosity and packing fraction in Table 2, maize starch exhibited the largest maximum volume reduction due to packing while sweet potato starch exhibited the lowest. The flow characteristics of the starch were measured using angle of Repose. The angle of repose of sweet potato starch was greater than those of maize starch. Angle of repose above $50^{\circ}$ is an indication of poor flow characteristics of powder. Both of the starches were within the limit.

The Carr's index and Hausner ratio predict the flow and compressibility of powders, Hausner ratio below 1.25 and Carr's index above between 5-15\% indicates good flow or good compressibility. 
Comparative Evaluation of Zea mays (L.) and Ipomoea batatas (L.) as a Pharmaceutical Excipient

The swelling power of sweet potato starch was higher than that of Maize starch this parameter is an indicator of disintegrating property of starch. It means that sweet potato starch may have better disintegrating property than other starches. But it is important to note that it is not the only mechanism of disintegration (15).

Table 2: Comparative studies of phytochemical properties of both starch powder.

\begin{tabular}{|c|c|c|}
\hline Parameter & Maize & Sweet potato \\
\hline Viscosity (pa-sec) & 5.34 & 8.28 \\
\hline Bulk Density(gm/ml) & 0.88 & 0.77 \\
\hline Tapped Density(gm/ml) & 0.96 & 0.90 \\
\hline Carr's Index & 8.3 & 14.4 \\
\hline Hausner Ratio & 1.09 & 1.16 \\
\hline Moisture content (\%) & 09 & 11 \\
\hline Moisture sorption capacity $(\%)$ & 2.5 & 7.5 \\
\hline Swelling capacity (\%) & 50 & 62.5 \\
\hline Hydration capacity & 2.29 & 2.41 \\
\hline Angle of repose & 31.38 & 33 \\
\hline Porosity $(\%)$ & 21.43 & 45.77 \\
\hline Packing fraction & 0.79 & 0.54 \\
\hline True density $\left(\mathrm{gm} / \mathrm{cm}^{3}\right)$ & 1.12 & 1.42 \\
\hline
\end{tabular}

Compatibility of Etoricoxib with maize and sweet potato starch was evaluated by IR spectra and found that both Etoricoxib is comptible along with maize and sweet potato starch (Fig. 2-3).
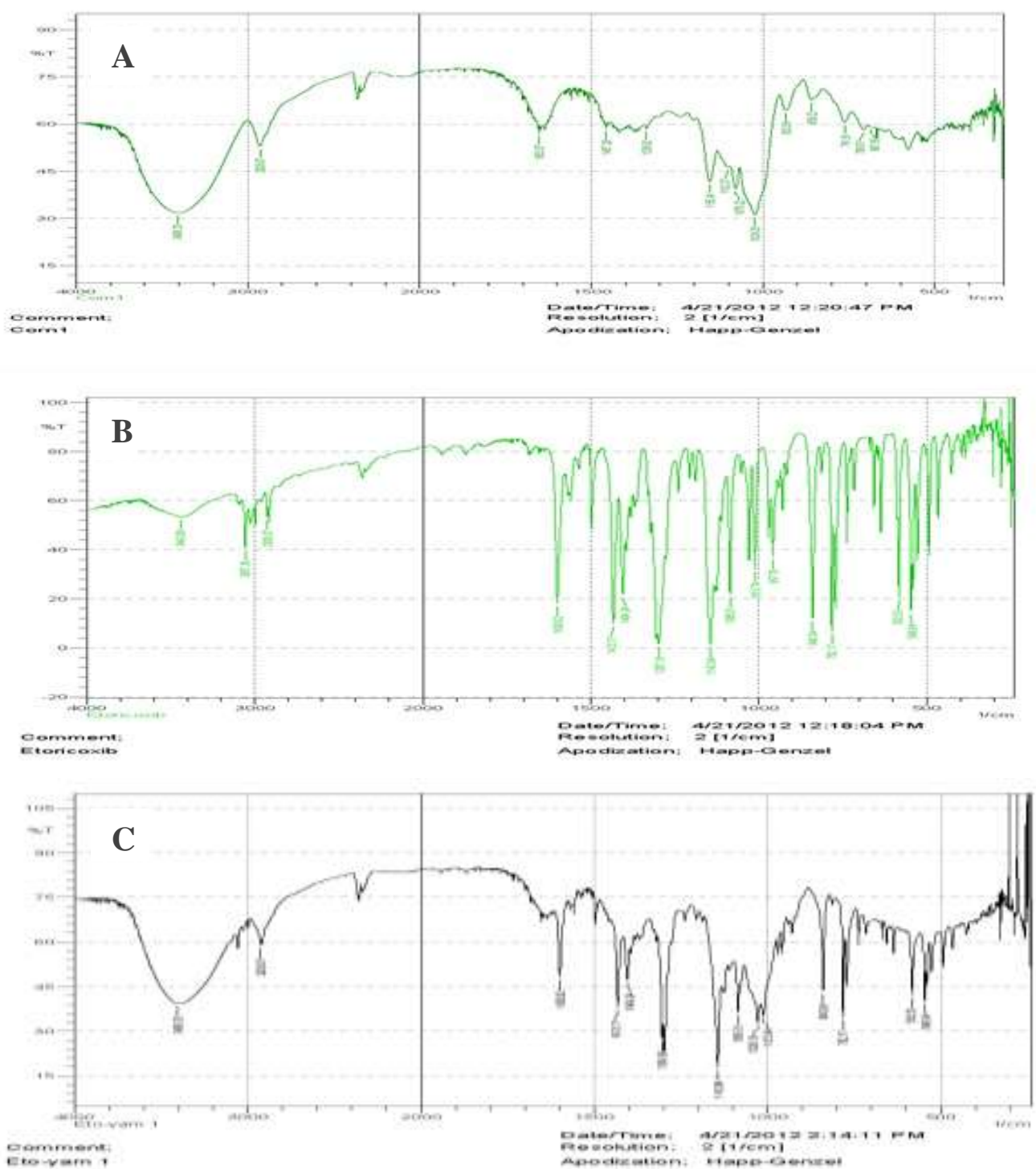

Figure 2: IR spectra of starch compatibility studies (A. Maize starch, B. Etoricoxib, C. Etoricoxib and Sweet potato starch). 

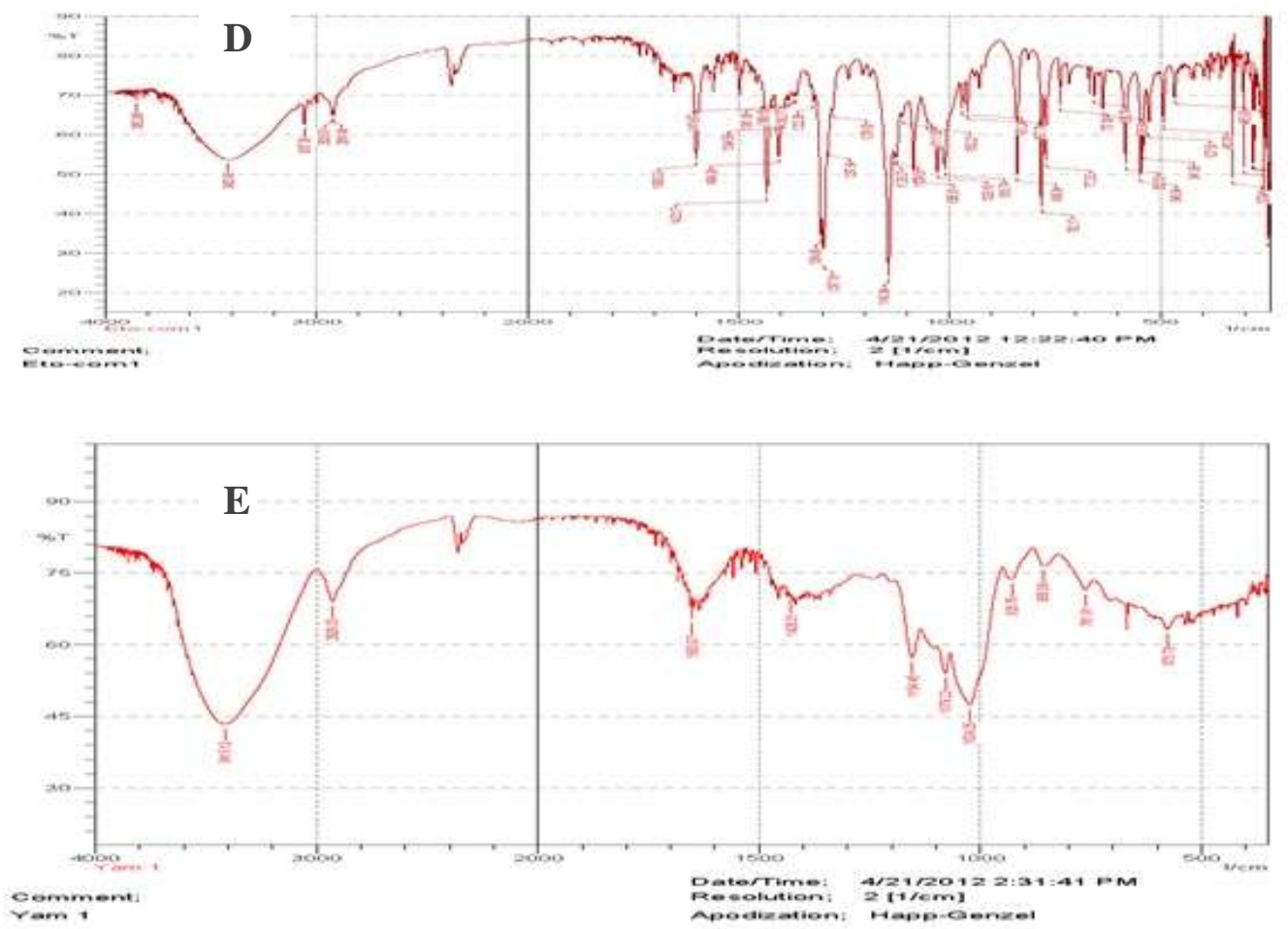

Figure 3: IR Spectra of starch compatibility studies (D. Etoricoxib and Maize starch E. Sweet Potato starch).

\section{Conclusion}

Sweet potato starch compared well to maize starch in physicochemical properties and could therefore serve as an alternative to maize starch as an excipient in the pharmaceutical industries especially in the manufacture of solid dosage forms.

\section{References:}

[1] Picker KM. 2004. Soft tableting: a new concept to tablet pressure sensitive drugs. Pharm. Dev. Technol.9:107-121.

[2] Hauschild K, Picker KM. 2004. Evaluation of a new compressed compound based on lactose and maize starch for tablet formulation. AAPS Pharm Sci. 6:1-12.

[3] Zhang Y, Law Y, Chakrabarti S. 2003. Physical properties and compact analysis of commonly used direct compression binders. AAPS Pharm Sci. 4:1-11.

[4] Heinemann C, Cardinaux F, Scheffold F, Schurtenberger P, Escher F, Conde-Petit B. 2004. Tracer micro rheology of $\gamma$ dodecalactone induced gelation of aqueous starch dispersions. Carbohydr. Polym. 55:155-161.

[5] Baldwin PM. 2001. Starch-granule associated proteins and polypeptides: a review. Starch/ Stärke. 53:475-503.

[6] Swinkels JJ. 1985. Compositions and properties of commercial native starches. Starch/ Stärke. 37:1-5.

[7] Parrott EL.1990. Compression. In: Augsburger LL, Hoag SW,eds. Pharmaceutical Dosage Forms: Tablets. New York, USA: Marcel Dekker, Inc., pp: 153-182.

[8] Rudnic EM, Kottke MK. 2002. Tablet dosage forms. In: Banker GS, and Rhodes C, eds. Modern Pharmaceutics, New York, USA: Marcel Dekker, Inc. pp: 333-391.

[9] Ghani A. 2003. Medicinal plants of Bangladesh. $2^{\text {nd }}$ Edition. The Asiatic Society of Bangladesh, Dhaka, Bangladesh.

[10] Iwuagwu MA, Okoli PC. 1992. The disintegrant properties of pregelatinized cassava and white yam starch. Pharm. World J. 9: 49 -53 .

[11] Ohwoavworhua FO, Kunle OO, Ofoefule SI. 2004. Extraction and characterization of microcrystalline cellusose derived from luffa cylindrica plant. Afr J Pharm Res. Develop.1(1):1-6

[12] Ohwoavworhua FO, Ogah E, Kunle OO. 2005. Preliminary investigation of physicochemical and functional properties of alpha cellulose obtained from waste paper - A potential pharmaceutical Excipient. J Raw Mat Res, 2:84-93.

[13] Rowe RC, Sheskey PJ, Quinn M. 2006.Handbook of Pharmaceutical Excipients Pharmaceutical Press. UK. 6th Edition.

[14] Ohwoavworhua FO, Adelakun TA and Kunle OO. 2007. A comparative Evaluation of the Flow and Compaction Characteristics of $\alpha$-Cellulose obtained from Waste Paper. Trop. J. Pharm. Res. 6 (1): 645-651

[15] Muazu1 J, Musa H, Isah AB, Bhatia PG, Tom1 GM. 2011. Extraction and characterization of Kaffir Potato Starch: A potential source of pharmaceutical raw material. J. Nat. Prod. Plant Resour. 1(2): 41-49.

[16] Ohwoavworhua FO, Adelakun TA. 2010. Non-wood fibre production of microcrystalline cellulose from Sorghum caudatum: Characterization and tableting properties. Indian Journal of Pharmaceutical Sciences, 72(3) : 295-301

[17] Caramella C. Novel methods for disintegrant characterization, part 1. Pharm technol., 1991, pp. 48-56. 